\title{
A CIDADE E A NATUREZA: A APROPRIAÇÃO, A VALORIZAÇÃO E A SOFISTICAÇÃO DA NATUREZA NOS EMPREENDIMENTOS IMOBILIÁRIOS DE ALTO PADRÃO EM SÃO PAULO ${ }^{1}$.
}

\author{
Wendel Henrique*
}

\section{RESUMO:}

O presente trabalho é uma busca pelas idéias de natureza e pelos processos de apropriação material e simbólica da natureza na cidade de São Paulo pelos agentes do mercado imobiliários. Nos casos estudados, o processo de apropriação, e mesmo de produção, da natureza na cidade está atrelado à valorização de áreas, bairros ou empreendimentos. Em São Paulo, onde a natureza se torna rara e não condizente com os processos atuais de produção e uso do território urbano, o acesso a este 'recurso' ou 'bem' se torna extremamente elitista e definido em função do poder econômico. A natureza, que deveria ser um valor de uso, se torna um valor de troca no mercado imobiliário. Desta forma, a natureza na cidade, para o mercado imobiliário, se torna apenas um atrativo financeiro e acaba por ser transformar em um objeto ou em uma idéia sofisticada passível de ser transformada em valor monetário.

\section{PALAVRAS-CHAVE:}

cidade, natureza, mercado imobiliário, valorização econômica, empreendimentos imobiliários.

\section{ABSTRACT:}

The present work is a search for the ideas and processes of material and symbolic appropriation of the nature in the city of São Paulo by real estate agents in the market. In the studied cases the process of appropriation and production of the nature in the city is linked with the valuation of areas, neighborhoods, condominiums or enterprises. In São Paulo, where the nature becomes rare and is not present in the current processes of production and use of the urban territory, the access to this 'resource' or 'merchandise' becomes extremely selective in function of the economic influence. The nature that would have to be a value of use becomes a value of exchange in the real estate market. The nature in the city for the real estate market is only one financial appeal and finishes for being transformed into a sophisticated object or idea which can be changed into monetary values.

\section{KEY WORDS:}

city, nature, real estate market, economic valuation, real estate enterprises.

\section{A cidade e a natureza}

No Renascimento, assistiu-se a uma mudança no modelo de concepção da natureza, onde passou-se de um padrão qualitativo para um quantitativo, uma ampliação da matematização do mundo, com o desencantamento da natureza e o seu enclausuramento em sistemas naturais e em jardins intencionalmente geométricos. Hoje, vive-se um novo período de profundas transformações nas idéias de natureza; além da permanência dos modelos quantitativos, observa-se uma restauração de uma idéia mítica da natureza, um reencantamento da natureza, não com um viés 'sobrenatural', mas, sim, seguindo um projeto específico de valorização financeira da natureza. Há, também, um claro movimento de incorporação da natureza à vida

* Geógrafo, Doutor em Geografia. Professor Adjunto de Geografia Humana, Departamento de Geografia e Programa de Pós-graduação em Geografia - Universidade Federal da Bahia. E-mail: wendelh@ufba.br. 
social. Instaura-se um projeto de reificação acentuada da natureza; sob uma abordagem mercadológica, a natureza vira objeto/ mercadoria nos mais variados segmentos da produção e dos serviços.

A busca por uma história das idéias e conceitos de natureza, principalmente a contribuição da Geografia, constituindo-se no alicerce teórico-conceitual deste trabalho, possibilitou o resgate do processo de transformação, incorporação e produção da natureza pelo homem.

O entendimento da incorporação da natureza à vida social pode ser uma possibilidade de recuperação da relação intrínseca entre o homem e a natureza (inserida ao território), pois esta deixa de ser uma externalidade à sociedade, externalidade criada com o projeto cartesiano e positivista, e passa a ser entendida como uma obra social, como um bem de toda a sociedade.

Se, no momento histórico atual, observase uma profusão de significados para a palavra natureza, a mesma constatação pode ser aplicada para a diversidade de interpretações e conteúdos da categoria natureza. Na cidade, local de moradia de grande parte da humanidade na atualidade, constata-se uma nova valorização estética da natureza, um 'simbolismo estético', construído pelo urbanismo e arquitetura, e, também, pelo mercado imobiliário.

Nesta abundância de entendimentos para a natureza, esta, na cidade, pode ser entendida como uma imagem, ou seja, como uma imitação ou reprodução; como símbolo, onde é algo que representa uma outra coisa, quer seja por associação ou convenção; e como signo, constituindo-se numa figura convencional que representa outra coisa no sentido literal ou abstrato.

Nesta sua imbricação com sociedade capitalista consumista, que valoriza a satisfação individual, a natureza se torna um mero artifício - substrato, objeto - fruto da ação do Homo
Faber. Como salienta Hannah Arendt (2000), ela adquire uma imagem que perpassa a fábula, o romântico e a cultura, que vai além da materialidade da paisagem, e que fica totalmente imbricada de valor monetário, financeiro, valor simbólico e real, adquirindo um caráter mundano, atrelado a um mundo movido por um motor hegemônico - o capitalismo.

A reaproximação ou um 'reencanto' do mundo urbano ocidental pela natureza, ou melhor, por uma idéia, dá-se num padrão de natureza moldado pelos interesses capitalistas. Sob a dinâmica atual do capitalismo, os grandes agentes do mercado global, nos mais diversos ramos da economia, das indústrias aos serviços, oferecem produtos e serviços para as classes com maior poder de consumo, que os colocam muito próximo da natureza. Uma natureza retrabalhada sob a forma de uma segunda natureza, reificada, incorporada, mercantilizada e produzida e vendida de acordo com as leis e objetivos do modo de produção atual - o lucro, a propriedade privada, os fetiches e sensibilidades do mercado.

A racionalidade instrumental capitalista cria e insere alguns objetos, como os esquilos, o urso panda, o plátano, os quais são simbólica, estrutural e funcionalmente mais avançados e mais perfeitos que a natureza, neste caso, que a natureza tropical pode criar. "Na realidade, quanto mais distante os objetos são da natureza, mais perfeitos eles são", conforme Santos (1999: 203).

Todas estas idealizações da natureza pelos habitantes da cidade mostram uma dupla determinação, sendo ambas relacionadas com a distância que a natureza (objeto a ser idealizado) está da vida cotidiana. De um lado, aqueles que estão mais próximos da natureza e que buscam a superação das dificuldades impostas por ela, e, de outro, aqueles que habitam lugares altamente tecnificados, longe da natureza e das suas limitações, buscando criar uma proximidade com a mesma.

Como coloca Greenbie (1988), para o executivo de uma grande corporação, que 
A cidade e a natureza: a apropriação, a valorização e a sofisticação da natureza

nos empreendimentos imobiliários de alto padrão em São Paulo, pp. 65 - 77

trabalhe no quadragésimo andar de uma torre de escritórios, a paisagem urbana pode não ser agressivamente ameaçadora, mas agressivamente excitante, um símbolo da vontade e do poder humano. Ele pode apreciar a presença de árvores na rua, mas esta apreciação pode não ser uma prioridade para ele, especialmente se ele mora numa boa casa num subúrbio verde. Para o balconista de uma das lojas do térreo, uma caminhada num parque no caminho para casa pode ser uma forma de recuperação de suas forças; porém, ele também pode preferir um caminho mais curto para seu apartamento com uma televisão e algumas plantas num vaso na janela, ou parar na paisagem genuinamente social de um bar. ${ }^{2}$

No mercado imobiliário, segundo Harvey (2000), especuladores (com apoio financeiro internacional), procurando maximizar seus ganhos a partir do aumento da renda da terra, por exemplo, estão atualmente reformando e reformatando ambientes metropolitanos de Xangai e Moscou, bem como de Londres e Nova lorque. A generalizada procura por rendas diferenciais cria diferenças geográficas na intensidade de investimento do capital, freqüentemente acarretando que regiões ricas em capital cresçam ricas enquanto regiões pobres em capital cresçam relativamente pobres. A diferenciação de estilos de vida, definidos pelo padrão econômico ou pelos valores comunitário ou de grupos, tem considerável importância, como, por exemplo, os distritos culturais gays, os assentamentos religiosos e as comunidades de ecologistas.

Criam-se, assim, nichos de mercado, os quais são explorados a partir da mobilização dos desejos humanos e na sua pseudoexclusividade, isto é, negando seu acesso a todas as pessoas. Do ponto de vista geográfico, definem-se territórios excludentes, que vendem desde a idéia de natureza até a de segurança. Outras propagam a idéia de uma natureza nos antigos modelos das cidades do interior, como um parque temático (Harvey, 2001). Também se tem o modelo das cidades verdes da Inglaterra. As idéias de natureza materializadas nos empreendimentos imobiliários criam objetos fixos que não podem ser facilmente removidos da configuração territorial do lugar.

Observa-se, através dos empreendimentos imobiliários na atualidade, o triunfo da apresentação sobre a significação, onde o engano se apresenta como verdadeiro. Criação de fantasias de natureza, onde os condomínios, as reservas, os parques naturais e os aquários - espaços altamente tecnificados - são apresentados como naturais. A natureza passa a ser associada a equipamentos e objetos cada vez mais técnicos.

\section{As primeiras associações entre a natureza na cidade e o mercado imobiliário}

No século XIX, inicia-se um movimento mais intenso de associação entre a natureza na cidade e a especulação imobiliária, com a construção de jardins e parques pelos agentes imobiliários, com o objetivo de valorização dos loteamentos construídos no entorno. A natureza na cidade passa a ser uma 'isca' ou uma imagem/símbolo. Isto posto num momento de grande valorização da natureza na cidade, quer seja por motivos estéticos (os passeios e a exibição de poder) ou pelas razões higienistas (de saneamento da cidade cada vez mais poluída pelas indústrias).

Reclus (1886) coloca duas formas de apropriação da natureza pelos empreendimentos imobiliários: uma direta e outra indireta. A apropriação da natureza, cada vez mais artificial, dá-se, como exemplo, nas costas marinhas, nos mais pitorescos penhascos e nas mais charmosas praias, em muitas localidades, monopolizada tanto pelos invejosos proprietários ou pelos especuladores que apreciam a beleza da natureza, em muitas vezes, na mesma forma como um 'cambista' valora uma barra de ouro. Em badalados lugares nas montanhas, uma similar forma de apropriação toma possessão dos habitantes: a paisagem é totalmente cortada em quadrados e vendidas em altas ofertas; cada curiosidade 
natural, a rocha, a caverna, a cachoeira, o glacial, tudo que faça o som de um eco, pode tornar-se propriedade privada.

Já a maneira de apropriação indireta da natureza dá-se na forma de sua utilização para a venda de produtos. Segundo Reclus (1886), prédios horrorosos, moinhos, oficinas, hotéis e depósitos tomam lugar na base dos penhascos; as propagandas em outdoors sujos e mentirosos são postadas, por exemplo em frente às Cataratas de Niágara, explorando as belezas da natureza para vender sua mercadoria ou seus remédios.

Segundo Munford (1998:461), "a cidade, desde o princípio do século XIX, foi tratada não como uma instituição pública, mas como uma aventura comercial privada, a ser afeiçoada de qualquer modo que pudesse aumentar a rotatividade e fazer subirem ainda mais os valores dos terrenos".

$\mathrm{Na}$ associação entre especulação imobiliária e a natureza, os incorporadores se apropriam de todos os locais charmosos e belos, os quais dividem em lotes retangulares, enclausurando os mesmos em muralhas uniformes onde são construídos mansões e casarões pretensiosos. Para os que passeiam pelos caminhos e trilhas, nestes pretensos espaços de campos a natureza não é mais do que representada por arbustos talhados e amontoados de flores que são entrevistas através das grades (Reclus, 2002).

Em Londres, observa-se o primeiro processo de valorização imobiliária a partir de uma associação com uma idéia de natureza. No início do século XIX, inicia-se a transformação das terras do Royal Marylebone Park num parque urbano - o Regent's Park. Todo o modelamento e estruturação deste parque foram financiados pelas empresas imobiliárias londrinas, cujo objetivo era a construção de casas no entorno deste novo parque, casas com vistas e terraços e 'villas' para pessoas ricas. A idéia era que a venda dos lotes e construções nas proximidades do parque pagaria os investimentos gastos no Regent's Park.
Segundo Munford (1998), na área do atual Regent's Park, que antigamente pertencia à Igreja Mary-le-Bow, estava sendo prevista a construção de um cemitério. Entretanto, o crescimento da cidade e a possibilidade de realização de lucros prevaleceram sobre o uso que se daria à área, que foi, portanto, loteada. "Quando a Coroa planejou o Regent's Park de Londres, o próprio parque foi abertamente considerado um artifício para aumentar o valor dos terrenos de propriedades vizinhas, pertencentes à Coroa Real." (p.414)

Neste mesmo movimento, mas em Paris, foi criado o 'Bois de Boulogne', cuja área foi doada à cidade por um empreendedor imobiliário, que era proprietário das terras do entorno do parque. As colinas e lagos artificiais, construídas seguindo o modelo inglês, tornaram - lugar uma área de sucesso junto à alta burguesia e aristocracia parisiense. Logo entrou 'na moda', valorizando imensamente o seu entorno (para reforçar, do mesmo proprietário das terras doadas para a construção do parque), que foi vendida como 'o céu para os ricos's.

Em Nova Iorque, a especulação imobiliária no entorno do Central Park também se apropria das referências à natureza, levando a super adensamento das áreas próximas. Segundo Munford (1998: 463-464), "o desejo de utilizar todos os metros quadrados de espaço alugável dominava o proprietário, mesmo quando a construção era para seu uso privado e não se destinava à simples especulação pecuniária. Em muitas cidades, durante o século XIX, isso reduziu o quintal dos fundos a uma área para secar roupas, e esta, por sua vez, foi reduzida em espaço, a tal ponto que muitas caras residências da Quinta Avenida, em Nova Iorque, eram construídas quase costas contra costas, como qualquer asilo de classe inferior, e não tinham nem perspectiva, nem ventilação. Mais uma vez, a empresa capitalista, hipnotizada pela sua própria preocupação com os ganhos, ultrapassava a si mesma, pois um plano congestionado não traz necessariamente o máximo de retorno imediato, nem tem probabilidade de permanecer bastante válido ou 
A cidade e a natureza: a apropriação, a valorização e a sofisticação da natureza

nos empreendimentos imobiliários de alto padrão em São Paulo, pp. 65 - 77

atraente para assegurar uma exploração lucrativa durante um longo período de anos."

Como as propagandas de empreendimentos imobiliários da atualidade (que serão analisadas posteriormente), em 1866, no Plano de Riverside, Illinois (EUA), a Riverside Improvement Company já fazia menção a sofisticação da natureza na cidade. Como mostra Capel (2002), a propaganda de Riverside mostra o encanto refinado da beleza silvestre, com paz e tranqüilidade, positivamente pitoresco e que contrasta com os ângulos retos que caracterizam as cidades modernas.

Sobre a especulação imobiliária atrelada à natureza em cidades brasileiras pode ser citado o caso de Porto Alegre, no final XIX e começo de XX, com a criação do Campo da Redenção, seu ajardinamento e loteamento do entorno. Segundo Segawa (1996:218), "aproveitamento de áreas tradicionalmente tidas como inúteis ou de árduo aproveitamento: sobre várzeas, charnecas, terrenos de altimetrias complicadas. Era a conquista da terra firme, aterros que acresciam à vizinhança urbana horizontes de expansão, enterrando miasmas e cobrindo superfícies infectas com um simulacro saudável de natureza. Terrenos outrora sem préstimo, os quais, mediante intervenções patrocinadas pelo poder público - nem sempre adequadamente amparado com recursos para iniciativas dessa escala [diferente da Europa e dos EUA, onde a intervenção no jardim era privada] (e sempre oficial, qualquer que seja a instância: autoridade colonial, provincial, municipal) - transformam-se em áreas valorizadas e vizinhanças valorizadas."

Mais recentemente, o processo de associação entre a natureza e o mercado imobiliário deu-se no Rio de Janeiro. Nesta cidade, a pressão do mercado imobiliária por áreas de beleza cênica foi importante na expansão urbana. De acordo com Abreu (1992), na década de 50 , com a possibilidade de renda fundiária esgotada na zona sul, com a verticalização e adensamento populacional em Copacabana e Ipanema e a proliferação das favelas, com a conseqüente diminuição do valor dos imóveis do entorno, aumentou a demanda por moradias à beira-mar. Na década de 60 , a concentração de renda aumenta e se efetiva a associação entre imóveis e áreas verdes como atrativo imobiliário. Esta situação, segundo Abreu (op.cit. :96-97), “levou a um processo drástico de remoção das favelas de locais valorizados da cidade (especialmente da Zona Sul), para que aí fossem construídas habitações de luxo (símbolos dessa mesma concentração), ou para que os morros fossem mantidos livres e desembaraçados, condição necessária para sua venda, pela empresa imobiliária, como 'áreas verdes'". Na década de 70 e 80 , através da ação do Estado na construção da auto-estrada Lagoa-Barra, ocorre a expansão urbana para a região da Barra da Tijuca e Jacarepaguá. Os empreendimentos imobiliários desta área de expansão do Rio de Janeiro marcam a febre por viver em um novo estilo - a oportunidade de 'viver no meio do verde', de 'integrar-se com a natureza' das vistas panorâmicas -, isto posto para um pequeno grupo privilegiado da população carioca.

A partir destes exemplos, constata-se uma apropriação da natureza, uma apropriação da apreciação estética da natureza, consistindo numa salvaguarda das suas belezas como forma de agregação de valor a uma propriedade privada, que passa, também, pela privação de sua componente estética, separando-a do olhar dos homens através de cercas ou muros, definitivamente ou impondo uma única forma de apreciação através da compra de um ingresso.

Cria-se uma diferenciação espacial da natureza na cidade de acordo com a estratificação social. Enquanto nas áreas nobres e valorizadas tanto dos centros quanto das periferias urbanas ricas o que se vê é uma natureza trabalhada e bem cuidada - tanto sob a forma de jardins ingleses, franceses ou bosques e lagos, um lugar para passeio e exibição, um lugar de prestígio -, nos bairros menos abastados, nas vilas, nos conjuntos habitacionais e nas periferias pobres, a natureza bruta (ou o mato?) e ainda 'não controlada' fazse presente, trazendo enchentes, inundações, 
doenças e frio.

No período histórico atual, em várias cidades do Brasil e do Mundo, qualquer objeto associado a uma idéia de natureza torna-se sinônimo de qualidade de vida e transforma-se em valor econômico, aumentando os preços dos apartamentos, casas, condomínios e edifícios. Especificamente em São Paulo, este processo pode ser observado em várias áreas da cidade, com especial concentração nas imediações dos parques urbanos e em bairros como: Vila Andrade, Moema, Morumbi, Brooklin Novo, Campo Belo, Granja Julieta, entre outros.

Em alguns destes lugares onde o que existe é apenas uma proximidade com uma idéia de natureza, uma vez que se tratam de empreendimentos localizados em já densas áreas residenciais e mesmo em outras, o que se observa é a manutenção de áreas verdes nas quais foram plantadas espécies exóticas. Praticamente todos os croquis de localização destes empreendimentos são impressos na cor verde e aproximam as áreas verdes - parques e praças. Além disto, ao lado da propaganda contendo a proximidade do 'verde', destacamse, sempre, a presença de shopping centers nas redondezas.

\section{A valorização imobiliária, a sofistificação e a elitização da natureza em São Paulo}

A cidade de São Paulo apresenta-se, material e esteticamente, como uma negação da idéia de natureza romântica e verde. Entretanto, encontram-se reunidos em seu espaço os traços de uma idéia de natureza romanticamente e globalmente padronizada pelos agentes do mercado imobiliário e grandes incorporadoras, que têm reafirmado o valor monetário da natureza. Em muitos casos, a valorização da natureza sempre verde nos empreendimentos imobiliários (Tabela 01) restringe-se apenas aos folhetos e material de propaganda, pois o que se observa, na realidade, é uma retirada da vegetação nativa (o que ainda restava) e, em outros casos, a manutenção de uma área verde na qual foram plantadas espécies exóticas - principalmente eucaliptos e palmáceas.

Muitos são os em preendin entos que negam a constnução social da natureza e todo o processo histórido de sua incomporação à vida cotidiana, conforme dem onstrado por Henrique (2004). Este é o caso doBrazilian Art (distrito do Itaim Bibi), numa rua privativa onde 'o verde nativo das matas brasileiras' ${ }^{5}$ está presente. Após todo o processo de ocupação do sítio urbano da cidade, de todo o desenvolvimento técnico da sociedade ocidental, encontrar verde nativo das matas brasileiras num bairro completamente urbanizado de São Paulo, com uma área verde por habitante, segundo dados do Atlas Ambiental de São Paulo (2003), de 3,86 $\mathrm{m}^{2} /$ habitante, não é apenas uma ilusão, como se transforma no mais puro ato enganador que o 'marketing verde' propaga. É a comprovação da alienação, do pagamento por um produto caro, a natureza nativa, mas que, na verdade, é o pagamento para ser enganado.

Em São Paulo, todas as áreas verdes públicas da cidade se tornam, pela propaganda dos empreendimentos, bens privados. Para ilustrar esta situação, utiliza-se o Helbor Grand Palais, que tem o 'privilégio de ter o parque do Ibirapuera como jardim' (Folha de São Paulo,10/ 09/2003). Já o Camp Life, na Vila Olímpia, vai além na posse da natureza na cidade, pois, a partir dos terraços dos apartamentos é possível uma vista da cidade, ou melhor, das suas terras - 'E você, dono de tudo, observando suas terras do alto'.

Outro exemplo que pode ser citado é o Green Phylosophy, construído pela Cyrela e Brazil Realty, no Panamby (Vila Andrade), que, além de valorizar a presença do Shopping Jardim Sul nas redondezas, apropria-se do Parque Burle Marx 'do outro lado da rua', além do 'parque privativo com quase $20.000 \mathrm{~m}^{2}$ a partir do próprio Green Phylosophy'. O empreendimento resgata, também, a idéia renascentista da relação entre a arte, arquitetura e natureza, mas de maneira invertida, pois a sua lógica é valorizar o verde. 
A cidade e a natureza: a apropriação, a valorização e a sofisticação da natureza

nos empreendimentos imobiliários de alto padrão em São Paulo, pp. $65-77$

Tabela 01 - Alguns empreendimentos imobiliários na cidade de São Paulo que fazem relação direta com uma idéia de natureza

\begin{tabular}{|c|c|c|c|c|c|}
\hline Nome do empreendimento & Logotipo & Referências & $\begin{array}{c}\text { Bairro } \\
\text { divulgado }\end{array}$ & Distrito & $\begin{array}{l}\text { Area verde } \\
m^{2} / \text { hab. }\end{array}$ \\
\hline $\begin{array}{c}\text { 1-Villag b Paian by } \\
\text { waxgans a.com brjpa samby }\end{array}$ & $\begin{array}{l}\text { Borboletal } \\
\text { coragaso }\end{array}$ & Parque butk Marx & Paiamby & VIEÁAdáde & 100,98 \\
\hline 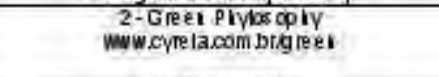 & Ramo de bambi & $\begin{array}{c}\text { Parque } \\
\text { Burk Marx } \\
\text { Sioping Jartin sıl }\end{array}$ & Pasamby & WhaAdrate & 100,98 \\
\hline $\begin{array}{l}\text { 3- Allue Morimbi } \\
\text { waw Liablis egall com bt/allie mon mbal }\end{array}$ & 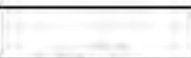 & Siopplig Jardm SII & Morumbi & VIGAIdrade & 10098 \\
\hline $\begin{array}{c}\text { l- Races da Mata } \\
\text { ww.ratzesdamatacem bl }\end{array}$ & $\begin{array}{c}\text { Letra fa } \\
\text { Azil - De i } \\
\text { verde - mata } \\
\text { Marrom - tera }\end{array}$ & $\begin{array}{c}\text { Siopplog Jardm Sil } \\
\text { parque } \\
\text { Burk Marx }\end{array}$ & Jardm Sil & VIleA Idade & 10098 \\
\hline S-vilie Am alm & Anore & $\begin{array}{c}\text { Parque } \\
\text { Euk Uan }\end{array}$ & Panamby & VIliadara & 10098 \\
\hline 6-Jardis do Portal & Anore & Portal do Morimbi & Morumbi & VIBACdacte & 100,98 \\
\hline 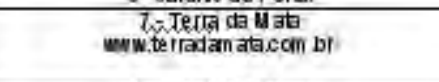 & Ramos com bilas & $\begin{array}{c}\text { Parque } \\
\text { Birk Marx } \\
\text { Siopplig Jandim sil }\end{array}$ & Jardm Sil & VIta Adracte & 10098 \\
\hline $\begin{array}{l}\text { 8-Panque Stratss } \\
\text { wew In rycon bi }\end{array}$ & $\begin{array}{l}\text { Notas in iscak ia } \\
\text { cor ve nde }\end{array}$ & $\begin{array}{c}\text { Colsglo } \\
\text { port Segur } \\
\text { estadio do Ior imbl }\end{array}$ & Morumbi & $\begin{array}{l}\text { Morumbl, divisa com } \\
\text { v/lissita. }\end{array}$ & $\begin{array}{l}239,0 \text { + (Morimb } \\
35,06 \text { crillaSatia) }\end{array}$ \\
\hline 9-VIIGH的有 & 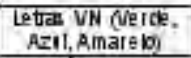 & $\begin{array}{c}\text { Clibe Hipto Said } \\
\text { Annaro }\end{array}$ & Clscara Fbra & Satto AmaID & 90,23 \\
\hline 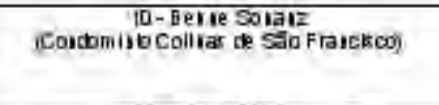 & Anore & $\begin{array}{l}\text { Slopplig } \\
\text { V/11 Lobor } \\
\text { Parq Ie } \\
\text { S1It Lobor. }\end{array}$ & $\begin{array}{l}\text { Colliad de saso } \\
\text { Fraucker }\end{array}$ & Propeqrero & 17.59 \\
\hline 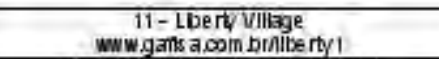 & & $\begin{array}{l}\text { Parque Raposo } \\
\text { Tayares }\end{array}$ & Nowa Pा meling & Rapcs a Tauare! & 60,95 \\
\hline $\begin{array}{l}12-\text { Mistgle-k paradis cesticl } \\
\text { waw.ezetccan bran ustique }\end{array}$ & & $\begin{array}{l}\text { Morimbi S कpplig. } \\
\text { DSD } \\
\text { Mankat P Pace }\end{array}$ & Brookili & $\mid \mathrm{tam}$ 6D| & 3,86 \\
\hline 13- Braclilan Aतt & Eactia & & Itam & Ifan Bण & 3,86 \\
\hline 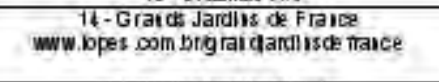 & landm & $\begin{array}{l}\text { Sioping DSD } \\
\text { slopplig Morumbi } \\
\text { Warket Pber }\end{array}$ & Campoteh & Canpo Beb & 71,12 \\
\hline 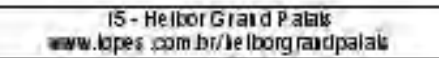 & Ramocom Dilas & $\begin{array}{l}\text { Parque do } \\
\text { bliapue ra }\end{array}$ & & VIs Markia & 0,93 \\
\hline 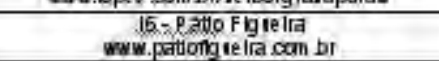 & Anore & Morumbi siopplig & VIG Mascot & Jabaquara & ID2 \\
\hline 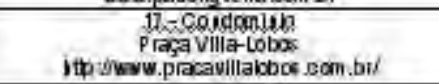 & $\begin{array}{l}\text { lostrume ib } \\
\text { miskea verde }\end{array}$ & $\begin{array}{l}\text { Shopping e Parque } \\
\text { vilta-Lobos }\end{array}$ & Alb de plinelices & $\begin{array}{l}\text { Alb de Pit re iré } \\
\text { QI Vila Leopoldila }\end{array}$ & $\begin{array}{l}18,99 \\
84,18\end{array}$ \\
\hline $\begin{array}{c}\text { 18-Paradko } \\
\text { www.dyaracon.brjaradks o }\end{array}$ & & siopplig wert & VIG Romala & $\begin{array}{l}\text { Penclues - divira } \\
\text { cem Lapd }\end{array}$ & $\begin{array}{l}5,94 \text { (Perdtzes) } \\
11,03 \text { (Lapa) }\end{array}$ \\
\hline $\begin{array}{c}19 \text {-Cainp Lffe } \\
\text { jth inuww.cam plite can.bil }\end{array}$ & Folla & $\begin{array}{c}\text { Avelicas Noug Farla } \\
\text { Lima }\end{array}$ & VIteolinpla & Lapa & $11, \mathbb{1}$ (Lapa) \\
\hline $\begin{array}{l}\text { 20-Uagravita } \\
\text { wwwinaglavitaccm }\end{array}$ & Sol & 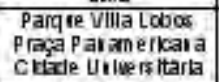 & Jandm Ale di L & VIti Lépolntıa & 18,99 \\
\hline 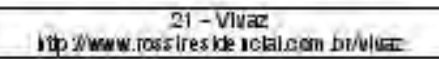 & & Horb F冋res tal & MaicteqI & MaIca्वा! & 75,68 \\
\hline
\end{tabular}

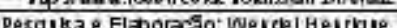

A propaganda afirma que no Green Phylosophy você vai mudar o seu conceito de natureza, pois é um lugar onde a 'natureza abraçou a arquitetura' e 'cada espaço é um meio ambiente', sendo 'uma reposta moderna à necessidade cada vez mais comum de integrar a natureza com os mais variados estilos de vida'.

Além da idéia de apropriação dos parques públicos, muitos empreendimentos em São Paulo fazem uso de uma idéia de proximidade com estes parques, uma vez que se tratam de empreendimentos localizados em 
já densas áreas residenciais. Os croquis de localização seguem uma tendência geral a aproximar, às custas do sacrifício da escala na representação cartográfica, as áreas verdes.

O Parque do Ibirapuera, a Cidade Universitária e o Parque Villa Lobos são as maiores vítimas destes croquis de localização.

Estes croquis, como representação da idéia de natureza que se vende, fazem uso maciço da cor verde na sua impressão e tendem a aumentar, exageradamente, a quantidade de áreas verdes do entorno ao empreendimento. Se um estrangeiro que chegasse a São Paulo, vendado, fosse pautar suas impressões apenas pelas árvores e áreas verdes destes croquis, com certeza irá reforçar a idéia de que o Brasil é um país ocupado inteiramente pelas florestas.

As maquetes, animações e vídeos (graças ao computador) dos empreendimentos também fazem uso recorrente das substituições das áreas construídas pelas áreas verdes.

Entretanto, o caso mais impressionante da anulação da cidade e supervalorização do verde dá-se no Villagio Panamby, um condomínio construído pela GAFISA, na região do Morumbi, mais especificamente na Vila Andrade, que é vendido como Panamby. O 'Villagio' é composto por 4 torres de alto padrão e a figura mostra uma das torres, com apartamentos de 4 suítes, $400 \mathrm{~m}^{2}$ e valor de $\mathrm{R} \$ 1.568 .000,00$ (um milhão, quinhentos e sessenta e oito mil reais), em 01/ $07 / 2003$. Além do predomínio do tom verde nas figuras de propaganda do empreendimento (conforme pode ser constatado nas figuras seguintes), os edifícios são, através de técnicas computacionais, inseridos no meio de uma grande floresta tropical, repleta de árvores de grande porte, e não no espaço urbano de São Paulo, nas proximidades da Marginal Pinheiros, na vertente oposta aos grandes prédios inteligentes da região da Avenida Berrini.

Os agentes do mercado imobiliário que constróem e vendem o Villagio Panamby fazem, no seu processo de superexploração do valor de troca de seu condomínio, um espaço social, econômica e geograficamente segregado do restante da cidade, através da sua supressão. Mesmo que esta análise seja marcada apenas pela observação dos materiais de propaganda, as idéias começam a se materializar no espaço. No ato de negar a cidade, por eliminação da paisagem urbana na imagem, o condomínio nega, também, a possibilidade de construção coletiva de uma natureza urbana, pois, excluído, mesmo que ideologicamente, de São Paulo e inserido no meio da tranqüilidade da floresta, o empreendimento evidencia e aquilata a satisfação individual dos seus moradores/ consumidores.

Pela análise dos dados do Atlas Ambiental de São Paulo (2003), percebe-se que a região da Vila Andrade (vendida como Panamby - na tentativa de repetição do sucesso mercadológico do Morumbi) possui uma das mais altas taxas de área verde por habitante da cidade. Entretanto, a aceleração do processo de construção de condomínios de alto padrão na região - em função desta natureza urbana ainda presente (e representada, em grande parte, por eucaliptos recentemente plantados, mostrando, mais uma vez, que a natureza na cidade é obra socialmente construída) - tende a diminuir este índice, quer seja pelo processo de substituição das áreas verdes pelas áreas construídas, quer pelo simples aumento da densidade populacional. Assim, a Vila Andrade terá uma menor quantidade de área verde a ser dividida por um maior número de moradores.

Concomitantemente ao 'projeto de vida com tanta natureza' no coração de São Paulo (aspecto negado pela imagem do empreendimento), o Villagio Panamby, que primeiramente possuía, segundo a propaganda de 24/03/2002 (Folha de São Paulo) 230.000 $\mathrm{m}^{2}$ só de área verde e posteriormente foi retificado para $230.000 \mathrm{~m}^{2}$ com muito verde (Folha de São Paulo, 01/07/2003), também explora a questão da segurança de viver num condomínio fechado, protegido com 'segurança Graber'. Desta forma, não é a natureza contra a qual a proteção de Graber seria desnecessária) a fonte de medp e insegurança 
A cidade e a natureza: a apropriação, a valorização e a sofisticação da natureza

nos empreendimentos imobiliários de alto padrão em São Paulo, pp. 65 - 77

nos homens, mas os próprios homens.

Ao lado da propaganda contendo a proximidade do 'verde', destaca-se, sempre, a presença de shopping centers nas redondezas. Afinal, apesar da idéia romântica da proximidade do verde, a sociedade moderna, ou melhor, as classes média e alta, não admitem a possibilidade de retorno ao estado primitivo da cidade ainda no meio da natureza. Ter árvores no entorno é importante, mas as infraestruturas básicas (água, luz, esgoto, telefone, antena de celular, TV a cabo, fibra ótica, hipermercado, delicatessen, pet shop, locadora de DVD, academia de ginástica, enfim, uma gama de serviços essenciais, 24 horas por dia) não podem estar longe do residencial (condomínio) natural.

Este é o caso do texto que vende o Alive Morumbi: 'O bosque do Alive Morumbi é um daqueles raros lugares numa cidade como São Paulo. Ocupando uma boa parte do terreno, a vegetação nativa recebeu cuidados especiais e uma gostosa alameda percorre toda sua extensão, em meio a espécies frutíferas e floríferas. Além de preservada, a área ainda vai ser ampliada com o plantio de mais 1.300 mudas, são quase $4.000 \mathrm{~m}^{2}$ de vegetação, praticamente a metade do terreno. Pegar jabuticaba no pé não é mais privilégio de quem mora no interior. Agora você vai fazer isto dentro da sua casa, à $400 \mathrm{~m}$ do Jardim Sul' (Folha de São Paulo, 31/ 08/2003).

Para tornar a situação da apropriação da natureza na cidade pelos empreendimentos imobiliários ainda mais interessante, um novo padrão global de natureza é inserido na cidade. A maior parte dos lançamentos imobiliários prédios e condomínios - é nomeado como pode ser constado nos empreendimentos já nominalmente citados, em línguas estrangeiras, especialmente inglês, francês e italiano.

Além da questão lingüística, o mais importante é que estes empreendimentos, que fazem uso de uma idéia de natureza como uma forma de aumento de seus preços, na maioria dos casos observados, introduzem uma idéia 'globalizada' de natureza, através, por exemplo, de esquilos e elementos da flora de outros climas. Esta natureza externa, padronizada, bane aquilo que poderíamos considerar como uma idéia de natureza brasileira.

Como por exemplo, o condomínio Villa Natura (Folha de São Paulo, 17/10/2002) é descrito: 'um degrau acima de tudo o que já existiu', com $92 \%$ da área voltada para o verde e o lazer, fazendo com que a temperatura na Chácara Flora, graças à densa arborização, seja em média três graus abaixo à da cidade. 'Os jardins do Villa Natura - ao todo são 11 trabalham com as cores e texturas de algumas plantas brasileiras que se assemelham a espécies clássicas européias, como as topiárias, nas paisagens mais ordenadas de primeiro plano; uma natureza idealizada, em que a presença do verde e da água produz uma atmosfera impregnada de calma e tranqüilidade'.

O Grands Jardins de France (Campo Belo) vai além na sua natureza idealizada. 'Os Grands Jardins de France são uma homenagem a um estilo de vida que valoriza, ao máximo, o conforto, a sofisticação e a privacidade. Um conceito que teve como fonte de inspiração os jardins franceses, os maiores jardins formais que se conhece. $\mathrm{E}$, principalmente, o charme dos castelos que eles rodeiam'.

Outro empreendimento, o Mustique - Le paradis est ici, uma obra da EZTEC, é um dos melhores exemplos da utilização de uma idéia de natureza padronizada para agregar valor ao imóvel. Ele se localiza no Brooklin, que 'retrata idéia de pequena cidade e a configura opção nobre de bairro residencial'. Na propaganda do empreendimento, afirma-se que 'a Natureza invade o condomínio e colore as ruas do quarteirão. Mais de 80 árvores já foram plantadas nas calçadas do quarteirão que abraça o Mustique, fazendo, do condomínio e de seu entorno, uma verdadeira ilha de verde, ar puro e cor, muita cor. São plátanos, espécie que atinge até sete metros de altura e tronco com $50 \mathrm{~cm}$ de diâmetro, cujas folhas ficam vermelhas no outono e verde-alface na 
primavera, tingindo o cenário com tonalidades únicas e trazendo sombreamento agradável, ideal para passeios a qualquer hora do dia. [...] A Natureza se faz presente em todos os recantos do condomínio através do paisagismo que criou livings com bancos e praças para relax e um agradável bate-papo, compartilhado pela vegetação exuberante reforçada por caramanchões e trepadeiras floríferas. ${ }^{6}$,

Estas propagandas introduzem um novo valor estético que, em muitos casos, não são condizentes com nosso clima e flora tropicais. Além disto, a introdução de novas espécies pode colocar em risco as nossas, como é o caso do empreendimento Mustique que também prevê esquilos alimentando-se nas árvores ao seu redor. Como propaganda, estas promessas podem parecer inofensivas, mas sua concretização pode representar uma transformação perigosa nas relações do homem com a natureza.

Em associação com idéia de natureza sempre verde, alguns empreendimentos fazem uso da tranqüilidade como uma virtude da natureza urbana. O já citado Camp Life, na Vila Olímpia, segundo a propaganda deste imóvel, 'a primeira chácara urbana de São Paulo', é, naturalmente, uma área privilegiada, pois 'em uma chácara o ar é sempre mais puro, e a prática de esportes torna-se ainda mais estimulante e saudável. O fôlego aumenta, os músculos ganham tonicidade e os resultados aparecem de maneira rápida e prazerosa. [...] Perfeito até para quem quer chegar em casa e, simplesmente, respirar. Descansar com a família como se nem estivesse em São Paulo ${ }^{7}$. Como se os bons tempos de sossego e ar puro estivessem de volta'.

Contraditoriamente, o mesmo marketing que vende a tranqüilidade e o ar puro da 'vila verde com áreas e ruas arborizadas', da 'vila dos cafés freqüentada por intelectuais e pessoas interessantes', da 'vila cultural com suas livrarias, peças de teatros e espetáculos internacionais', afirma que a reestruturação urbana da Vila Olímpia favoreceu a abertura de grandes vias de circulação, onde as 'chácaras deram lugar à modernidade'. A tranqüilidade da Vila Olímpia cedeu espaço para os edifícios inteligentes que apagam os traços culturais e sociais do passado mítico valorizado primeiramente pela propaganda. Toda a infraestrutura modernizante da Vila Olímpia acabou por tornar o lugar o antônimo do sossego, inclusive com o adensamento do tráfego aéreo em Congonhas, com aviões decolando ou se aproximando da pista do aeroporto sobre o bairro.

Aliando-se à idéia da natureza como um elemento de consumo exclusivo para as classes altas da cidade de São Paulo, criam-se verdadeiros espaços de segregação no interior do tecido urbano paulistano, como o já mencionado Villa Natura, na região da Chácara Flora (Santo Amaro), onde o apartamento mais barato custava $\mathrm{R} \$ 287.000,00$. E renega-se sua inserção no tempo e no ritmo da metrópole, reforçando a idéia da alienação da cidade, uma vez que, segundo a propaganda, 'as ruas são sinuosas para evitar o tráfego de passagem e manter apenas o fluxo interno dos moradores. E muito arborizadas, para oferecer a quem passa o prazer de um passeio'. Neste bairro, onde a 'Natureza, o Lazer e a Tranqüilidade', estão associados, criando uma 'reserva de vida', cria-se um espaço da exclusão, definido pelo padrão econômico dos moradores, um grupo 'seleto que valoriza o alto padrão de vida e o contato permanente com a natureza'.

Talvez o empreendimento imobiliário que sintetize todos os aspectos da apropriação ideologizada da natureza no mercado de imóveis em São Paulo seja o Condomínio Praça Villa-Lobos (abril/2004). O próprio material de propaganda faz referência à super-valorização da natureza nas cidades pelo mercado imobiliário, escrevendo que 'todos os empreendimentos mais valorizados dos bairros nobres de São Paulo estão voltados para praças'. Estão presentes na venda do empreendimento as seguintes questões, já detalhadas para os empreendimentos anteriormente analisados: a privatização da 
A cidade e a natureza: a apropriação, a valorização e a sofisticação da natureza

nos empreendimentos imobiliários de alto padrão em São Paulo, pp. 65 - 77

natureza na cidade, materializada nos parques e praças públicos; o consumo da natureza como um objeto raro, requintado e exclusivo para as classes de alto poder econômico; a segregação urbana; e a venda da idéia de natureza verde, mas associada ao conforto da vida citadina e suas possibilidades de consumo nos shopping centers. Entre os diferenciais únicos, segundo o sítio de divulgação do empreendimento na Internet. No Condomínio Praça Villa-Lobos destaca-se:

$13.000 \mathrm{~m}^{2}$

- Praça exclusiva e privativa de

- Único com acesso por alameda particular: Alameda Villa-Lobos;

- Único com entrada privativa para o Shopping Villa-Lobos. Este é o único residencial onde os moradores podem ir a pé, a qualquer hora, durante o horário de funcionamento do shopping:

parque;

- Único com vista permanente para o

- Alto de Pinheiros tem ruas arborizadas e muitas praças que garantem a presença do verde [segundo o Atlas Ambiental de São Paulo (2003), o índice de área verde por habitante no distrito onde se localiza este condomínio é de $18,99 \mathrm{~m}^{2} / \mathrm{hab}$.];

- Alto de Pinheiros é o bairro menos violento de São Paulo (Gazeta Mercantil, 2003);

- Localização sem igual, única, vizinha ao Shopping e ao Parque Villa Lobos, cercada de segurança.

Os empreendimentos aqui mostrados, uma parcela pequena da grande oferta encontrada diariamente nos jornais, reforçam a questão da mudança de perspectiva na relação do homem com a natureza, passando, como já foi observado nos capítulos anteriores, de uma ação na natureza visando os aspectos de vida coletivos, a sobrevivência do grupo, para um padrão individualista, segregatório e egoísta de consumo da natureza, enclausurada nestes condomínios e de usufruto apenas de seus moradores, ou melhor, consumidores. Assim, a natureza na cidade não é um bem coletivo, não é um objeto socialmente compartilhado, é uma mercadoria exclusiva que 'o dinheiro' pode comprar.

\section{Considerações Finais}

A relação que nossa sociedade possui hoje com a natureza, ou com o território onde se insere a natureza, dá-se num "mundo que a técnica construiu para nós, somos hipnotizados pela lei do número ${ }^{8}$, um mundo geométrico das quantidades e valores econômicos e não das qualidades e valores fraternais. Assim, a natureza hoje se constitui, de acordo com uma proposta de Lenoble (1969) numa 'coisaimagem', muito mais imagem do que coisa. Nesta relação, os homens não enxergam os fenômenos sociais, políticos ou econômicos que penetram na idéia de natureza; eles continuam a ver apenas uma imagem romântica da natureza, que é captada e apropriada pelos empreendimentos imobiliários nas grandes cidades.

Infelizmente, mesmo com todas as utopias do urbanismo moderno, a cidade e a natureza passam a ser, segundo Rodrigues (2001:213), "medidas e mediadas pelo valor de troca, incessantemente alterado no processo indissolúvel" e a volta do verde à cidade é uma forma de apropriação da natureza como propriedade privada.

Neste mundo da fantasia e da exploração capitalista, muitos empreendimentos imobiliários iniciam um processo de associação com uma das várias idéias possíveis de natureza na atualidade. Em comum, todos eles utilizam a natureza como uma das principais armas para sua valorização.

Mas, o que se observa é a deterioração das áreas verdes, onde o abandono e falta de manutenção faz com que estes espaços sejam vistos pelos moradores como sinônimos de lugares perigosos e violentos. A natureza, na cidade sem controle e sem manutenção, retoma 
a sua imagem de perigo e o seu aspecto hostil. O jardim bem cuidado acaba por se transformar em mato.

A natureza na cidade é uma necessidade, que, infelizmente, foi engolida e propagada pelas possibilidades de consumo da moradia, necessidade criada de acordo com a renda do comprador dos imóveis. Assim, a natureza na cidade torna-se uma mercadoria para poucos consumidores, escolhida em função da obtenção de aumento do valor de trocas pelos empreendedores imobiliários. Para os agentes do mercado imobiliário, a natureza na cidade não é uma necessidade coletiva, e a exclusão é exercida à serviço da acumulação.

\section{Notas}

1 O tema que apresentamos faz parte de nossa tese de doutoramento "O Direito a Natureza na Cidade: ideologias e Práticas na História", desenvolvida junto ao Curso de Pós-Graduação em Geografia da Unesp - Campus de Rio Claro, sob orientação do Prof. Dr. Pompeu Figueiredo de Carvalho. O texto completo da tese pode ser encontrado em http://www. biblioteca. unesp.br/bibliotecadigital/ document $/$ did $=2632 \&$ print $=y$

2 "To the corporate executive on the forthieth floor of an office tower, the urban landscape may not be aggressively threatining but aggressively exciting, a symbol of human purpose and power. He may enjoy the presence of trees on the street far below, but that enjoyment may have very low priority with him, especially if the has a lush home in a green suburb. To the clerk leaving an anonymous desk on a lower story, a walk through a park on the way home may be restorative; but the may prefer to elbow his way home by the shortest route to an apartment with a television set and few potted plants on the window sill, or stop off in the purely social landscape of a local bar". (Greenbie, 1988:73)

3 Capel (2002).

4 Atlas Ambiental de São Paulo, 2003

5 Todas as citações com aspas simples referem-se aos materiais de publicidade dos empreendimentos estudados e foram usadas desta maneira para se distinguirem das citações acadêmicas.

${ }^{6}$ Folha de São Paulo (03/03/2002).

${ }^{7}$ Novamente observa-se a idéia da negação da cidade para a valorização das virtudes da natureza.

${ }^{8}$ Lenoble (1969:205)

\section{Bibliografia}

ABREU, Maurício de Almeida. A Cidade, a Montanha e a Floresta. In: ABREU, M. A. (org.). Natureza e Sociedade no Rio de Janeiro. Rio de Janeiro: Prefeitura Municipal do Rio de Janeiro, 1992, pp. 54-103.

ARENDT, Hannah. A Condição Humana. $10^{a}$ ed. Rio de Janeiro: Forense Universitária, 2000.

CAPEL, Horácio. La Morfología de las Ciudades. Vol.l - Sociedad, cultura y paisaje urbano. Barcelona: Ediciones del Serbal, 2002.

CHOAY, Françoise. O Urbanismo. Utopias e realidades: uma antologia. São Paulo: Ed.
Perspectiva, 1992.

FOLHA DE SÃO PAULO 03/03/2002

FOLHA DE SÃO PAULO 17/10/2002

FOLHA DE SÃO PAULO 01/07/2003

FOLHA DE SÃO PAULO 31/08/2003

FOLHA DE SÃO PAULO 10/09/2003

GREENBIE, Barrie B. The Landscape of Social Symbols. In, NASAR, Jack L. (edt.) . Environmental Aesthetics. Theory, Research \& Applications. Cambridge: Cambridge University Press, 1988, pp. 64-73. 
HARVEY, David. Justice, Nature and the Geography of Difference. Oxford: Blackwell Publishers Itd, 1996.

HARVEY, David. Spaces of Hope. Berkley: University of California Press, 2000.

HARVEY, David. Spaces of Capital. Towards a Critical Geography. New York: Routledge, 2001.

HENRIQUE, Wendel. O Direito a Natureza na Cidade. Ideologias e práticas na história. Rio Claro: IGCE/UNESP, 2004. (Tese de Doutorado)

LENOBLE, Robert. História da Ideia de Natureza. Lisboa: Edições 70, 1969.

MUMFORD, Lewis. A Cidade na História. Suas origens, transformações e perspectivas. 4a. ed. São Paulo: Martins Fontes, 1998.

RECLUS, Élisée. A New Physical Geography. Vol II - The Ocean, Atmosphere and Life. New York: D. Appleton \& Cia., 1886.
RECLUS, Élisée. Du sentiment de la nature dans le societés modernes et autres textes. Paris: Édition Premières Pierres, 2002.

RODRIGUES, Arlete Moysés. Produção do espaço e ambiente urbano. In, SPOSITO, M.E.B. (org.). Urbanização e Cidades Médias. Perspectivas Geográficas. Presidente Prudente: UNESP/ GAsPERR, 2001, pp. 211-230.

SANTOS, Milton. A Natureza do Espaço - técnica e tempo, razão e emoção. 3. ed. São Paulo: HUCITEC, 1999.

SÃO PAULO (Prefeitura). Atlas Ambiental de São Paulo. São Paulo: PMSP, 2003.

SEGAWA, Hugo. Ao Amor do Público. Jardins no Brasil. São Paulo: Studio Nobel, 1996.

Trabalho enviado em abril de 2006

Trabalho aceito em setembro de 2006 